\title{
A poesia de Pedro Munhoz em um diálogo com o conceito de solo: análise de uma pratica pedagógica para a formação de professores
}

Pedro Munhoz's poetry in a dialogue with the concept of soil: analysis of a pedagogical practice for teacher training

La poesía de Pedro Munhoz en diálogo con el concepto de suelo: análisis de una práctica pedagógica para la formación del profesorado

Richard Lima Rezende

Mestrando, UFLA, Brasil richardbio2015@gmail.com

Heitor Vieira Passos

Graduando, UFLA, Brasil heitorpassos97@gmail.com

Antonio Fernandes Nascimento Junior

Professor Doutor, UFLA, Brasil toni-nascimento@yahoo.com.br 


\title{
Revista Científica ANAP Brasil
}

\author{
ISSN 1984-3240 - Volume 13, número 31, 2020
}

\section{RESUMO}

Este trabalho busca analisar uma prática pedagógica sobre o ensino do conceito de solo que aconteceu durante um curso de verão na Universidade Federal de Lavras. Com o objetivo de entender como ela foi concebida por um grupo de universitários, foi colocada uma avaliação para que os envolvidos expressassem os pontos positivos e os pontos a serem melhorados da aula em questão. Para analisar as falas dos envolvidos utilizamos um método de categorização de falas, onde as mesmas foram agrupadas em três categorias. A primeira diz respeito à dinamicidade da aula que proporcionou a participação dos envolvidos. A segunda categoria é referente ao domínio do conteúdo e preparo que os professores demonstraram ter durante o desenvolvimento, sendo um aspecto fundamental do saber do docente. A terceira se constitui pelas falas relacionadas à poesia utilizada como recurso problematizador, se mostrando um meio interessante de aliar a sensibilidade da arte ao olhar científico sobre o mundo de modo a formar cidadãos mais completos quanto seres humanos. Conclui-se que a proposta pedagógica foi concebida positivamente pelos envolvidos e que ser dinâmica e participativa é uma de suas essências, além do fato de os professores se apresentarem preparados e seguros quanto ao domínio do conteúdo e problematizarem a realidade pela poesia.

PALAVRAS-CHAVE: Ensino. Solo. Metodologia.

\section{ABSTRACT}

This work seeks to analyze a pedagogical practice on teaching the concept of soil that happened during a summer course at the Federal University of Lavras. In order to understand how it was conceived by a group of university students, an assessment was made so that those involved expressed the positive points and the points to be improved in the class in question. To analyze the speeches of those involved, we used a method of categorizing speeches, where they were grouped into three categories. The first concerns the dynamics of the class that provided the participation of those involved. The second category refers to the domain of content and preparation that teachers demonstrated to have during development, being a fundamental aspect of the teacher's knowledge. The third is constituted by the speeches related to poetry used as a problematizing resource, proving to be an interesting way of combining the sensitivity of art to the scientific view of the world in order to form more complete citizens as well as human beings. We conclude that the pedagogical proposal was positively conceived by those involved and that being dynamic and participatory is one of its essences, in addition to the fact that the teachers are prepared and confident about the domain of the content and problematize the reality through poetry.

PALAVRAS-CHAVE: Teaching. Soil. Methodology.

\section{RESUMEM}

Este trabajo busca analizar una práctica pedagógica sobre la enseñanza del concepto de suelo que tuvo lugar durante un curso de verano en la Universidad Federal de Lavras. Con el fin de comprender cómo fue concebido por un grupo de estudiantes universitarios, se realizó una evaluación para que los involucrados expresaran los puntos positivos y los puntos a mejorar en la clase en cuestión. Para analizar los discursos de los involucrados, utilizamos un método de categorización de discursos, donde se agruparon en tres categorías. El primero se refiere a la dinámica de la clase que proporcionó la participación de los involucrados. La segunda categoría se refiere al dominio del contenido y la preparación que los maestros demostraron tener durante el desarrollo, siendo un aspecto fundamental del conocimiento del maestro. El tercero está constituido por los discursos relacionados con la poesía utilizada como recurso problematizante, demostrando ser una forma interesante de combinar la sensibilidad del arte a la visión científica del mundo para formar ciudadanos más completos, así como seres humanos. Concluimos que la propuesta pedagógica fue concebida positivamente por los involucrados y que ser dinámico y participativo es una de sus esencias, además del hecho de que los maestros están preparados y confiados sobre el dominio del contenido y problematizan la realidad a través de la poesía.

PALAVRAS-CHAVE: Enseñanza. Suelo. Metodología. 


\section{INTRODUÇÃO}

"Não se desiste da luta quando matam um Sem Terra" é um emblema de vários grupos de pessoas que buscam sua sobrevivência em uma sociedade onde a terra não está distribuída igualmente entre seus integrantes. Aqui no Brasil, o Movimento dos Trabalhadores Sem Terra (MST) compreende diversas famílias que lutam pela reforma agrária, indo contra os latifúndios improdutivos que correspondem a grandes extensões de terra dominados por pequenos grupos de pessoas.

Em tom de resistência ao modelo de sociedade em que a distribuição da terra é desigual, o poema de Pedro Munhoz foi escrito, o qual finaliza sua obra poética com o fragmento que iniciou este texto, intitulada "Quando matam um Sem Terra". Este poema foi escolhido para compor uma prática pedagógica para se ensinar o conceito de solo, tema este que está intimamente relacionado ao termo popular "terra", como veremos a seguir, que se encontra problemático a respeito de seu ensino, ao mesmo tempo que podemos divulgar um caminho alternativo para o ensino deste tema com grande potencial para uma abordagem sociocientífica (ASC) a partir deste poema.

A ASC em sala de aula possibilita aos estudantes se aproximarem do professor, onde há mais momentos dialógicos entre estes personagens, além de que os primeiros podem trazer para o processo de ensino e aprendizagem as experiências de seus contextos de vida. Sendo assim, a problematização da realidade, proporcionando aos estudantes (re)significarem a realidade confrontando-a aos seus cotidianos, se aproxima do pensamento do educador Paulo Freire, reforçando a importância da problematização na formação dos sujeitos (SANTOS \& MORTIMER, 2009).

A aula em questão foi planejada, construída e ministrada durante um curso de verão deste ano de 2020. Antes de nos atentarmos aos detalhes desta proposta pedagógica, daremos um breve olhar para o cenário do ensino do conceito de solo e para a formação de professores, de modo a refletir sobre suas dicotomias, principalmente, neste caso, em relação à arte e ciência.

\section{ENSINO DO CONCEITO DE SOLO: ALGUMAS CONSIDERAÇÕES}

O conceito de solo é um tema abordado amplamente durante a escolarização básica, mas o enfoque para este trabalho é o ensino fundamental. Iniciando um panorama por um documento mais antigo, mas que influenciou a construção de materiais didáticos e o trabalho educativo das escolas durante as últimas duas décadas, Lima (2005) traz que, segundo os Parâmetros Curriculares Nacionais (PCN) do Ensino Fundamental, a temática dos solos deve ser abordada de modo processual e gradual, sendo que se divide em quatro etapas e cada uma é abordada em seu respectivo ciclo.

Do primeiro ao segundo ciclo do Ensino Fundamental a abordagem adequada concentra-se na perspectiva introdutória do assunto, sem perder de vista as características transversais e multidisciplinares do conteúdo, de forma a direcionar o olhar dos estudantes para que identifiquem e diferenciem as diferenças e semelhanças que surgem nos ambientes, considerando os fatores bióticos, como a presença ou ausência de seres vivos, assim como os fatores abióticos, tais como a umidade e granulosidade do ambiente, além de se relacionar com 


\section{Revista Científica ANAP Brasil}

ISSN 1984-3240 - Volume 13, número 31, 2020

as interações que decorrem da formação dos solos, o que demanda a abordagem das interações entre os seres vivos e as dinâmicas de erosão, fertilidade, processos de decomposição dentre outros (LIMA, 2005)

Nos terceiro e quarto ciclos os solos são tratados em seus componentes físico-químicos, além de se abordar mais detalhadamente sua origem e a relação que possui com as dinâmicas dos ciclos biogeoquímicos, tendo como exemplo o ciclo hídrico e seus efeitos na paisagem tanto do campo quanto do meio urbano. Nessa etapa conclusiva do Ensino Fundamental, as interesses econômicos também são abordados, retomando os conceitos previamente trabalhados nos ciclos anteriores, mas com maior aprofundamento e integração entre as características e propriedades dos solos e as interações que decorrem das mesmas e seus impactos na vida econômica e na saúde dos indivíduos, tanto das cidades quanto do meio rural, o que levanta temáticas relacionadas à poluição, de maneira geral, degradação dos ambientes urbanos e rurais para o atendimento de demandas do capital, o uso de práticas agrícolas ultrapassadas (a exemplo das queimas), dinâmicas sociais decorrentes das relações de poder que o ser humano possui com o solo, dentre outros temas transversais e multidisciplinares (LIMA, 2005).

Este autor aponta em seu trabalho propostas de atividades a serem realizadas como por exemplo: a utilização de imãs em diferentes amostras de solo para se evidenciar a polaridade presente em decorrência das diferentes composições, ou a construção de perfis geográficos que vão desde a rocha sã até a formação de um solo com seus perfis e a rocha mãe. Outra pratica citada é a construção de um filtro para a investigação da capacidade de filtragem do solo em relação a água que chega das chuvas e cai nos rios e demais corpos d'água, além da montagem de simulações de terrenos com e sem vegetação para se avaliar a diferença dos impactos das chuvas entre ambientes preservados e ambientes degradados por ação humana (LIMA, 2005). Deslocando o panorama para um documento mais atual, a Base Nacional Comum Curricular (BNCC) apresenta o ensino do solo em seus aspectos biogeoquímicos nos anos finais, por meio de uma abordagem sistêmica, que considera as particularidade dos diferentes climas e formas de vida ao redor do planeta, em ambientes preservados, assim como em locais sob o efeito de ações antrópicas, com foco nos ecossistemas brasileiros e em suas particularidades de radiação solar, pluviosidade e demais propriedades (BRASIL, 2017).

O documento possui propostas de atividades relacionadas ao ensino de solos pautadas no estímulo das sensações dos estudantes ao se observar amostras e classifica-las quanto a cor, textura, odor, umidade, granulosidade e outros aspectos perceptíveis ao tato, a visão e ao olfato. Tendo em mente a interação do solo com as demais formas de vida, a BNCC sugere atividades, vivenciais ou por meio de experimentos, que permitam a constatação das formas de vida presentes no meio, seja por plantio de amostras vegetais, seja por observação de perfis geográficos no intuito de trabalhar a importância do solo para o ciclo da água, desde a sua captação até o momento em que retorna para os corpos d'água.

Contudo, Oliveira (2014) traz que os solos são mal abordados dentro das escolas, visto que o conceito de solo é variado, pois não se destaca os quesitos da educação formal, mas as definições que também surgem nos saberes informais, como os diferentes significados que os solo apresenta para um trabalhador rural e para um arquiteto. Para o primeiro, o solo é visto como fonte de vida e renda, para o segundo, a fundação necessária à construção de um edifício. 
Nesse sentido os livros didáticos e paradidáticos apresentam-se como os recursos mais recorrentes nas escolas, sendo que apresentam informações deficitárias ou ultrapassadas, uma vez que seus conceitos são, muitas vezes, estáticos e não acompanham as novas pesquisas acerca da temática, onde há a valorização de processos mecânicos de ensino, no qual o estudante concentra-se na memorização de conceitos fragmentados. Nesta condição, os conceitos ora apenas ligados aos interesses agronômicos, ora relacionados aos aspectos geológicos, sem se estabelecer uma conexão entre os conhecimentos relativos ao ensino de solos (LIMA, 2005, p. 387-388).

Partindo das breves considerações a respeito do ensino do tema "solo", direcionaremos a reflexão para a formação de professores, etapa esta que professores pesquisadores e professores em formação podem agir no sentido de superar os obstáculos históricos que impedem a prática docente de ocorrer consistentemente e com qualidade. Além disso, levaremos em consideração a relação entre arte e ciência na formação de.

\section{FORMAÇÃO DE PROFESSORES: AS DICOTOMIAS}

Os saberes desenvolvidos e construídos pelo ser humano vem antes mesmo dos registros rupestres ou demais marcas culturais da passagem de nossa espécie pelo mundo. Isso quer dizer que as formas de conhecimento que proporcionaram estarmos vivos aqui hoje foram suficientes, legítimas e variadas ao longo de nossa evolução. Hoje temos como exemplo o mito, a filosofia, a ciência, entre outros, a arte. Para estes dois últimos elementos do saber humano, encará-los como opostos ou incompatíveis pode dificultar uma leitura mais ampla e aprofundada da realidade, uma vez que são segregadas partes do conhecimento que, segundo Rangel e Rojas (2014), é global.

Estas autoras ao olharem para a formação de professores discutem que a dicotomização estabelecida nos ambientes acadêmicos, estes que são uma das etapas que formam nossos professores, tende a separar o saber artístico do saber científico, o que, ainda segundo elas, pode dificultar a formação de um docente e pesquisador que compreenda o mundo pela sensibilidade e, ao mesmo tempo, pelo rigor científico (RANGEL \& ROJAS, 2014). Assim sendo, na prática em sala de aula, a visão dicotômica desenvolvida no professor será colocada, também, aos estudantes, influenciando diretamente em como estes sujeitos conceberão os elementos culturais da criação humana, a arte e a ciência durante o processo de ensino e aprendizagem. Na mesma direção, a dicotomização dos saberes não foi percebida somente entre a arte e a ciência, mas nos aspectos que compreendem a formação do profissional da educação. Nas licenciaturas, por exemplo, o saber científico é mais valorizado em detrimento ao saber pedagógico-didático; o que se encontra inversamente nas pedagogias (LIBÂNEO, 2015; GATTI, 2010). Este fato, além de poder provocar uma formação incompleta, considerando que o domínio do conteúdo é uma das essências do saber do professor, assim como os saberes pedagógicos, também, a dicotomização entre os saberes artístico e científico tende a agravar ainda mais uma formação fragmentada, tanto do professor quanto dos estudantes que serão mediados pelo seu exercício profissional. 
Associar arte e ciência na construção de saberes é o mesmo que associar razão e emoção, objetividade e sensibilidade, lógica, intuição e criação. Dessa forma, superam-se fragmentações e rupturas, para que se possa compreender, de modo mais abrangente, o mundo e as relações dos homens entre si e com a natureza (RANGEL \& ROJAS, 2014, p. 74-75).

Partindo da ideia de que arte e ciência em diálogo é fundamental para o ser humano se construir sensivelmente por meio de olhares objetivos e racionais, não descartando a emoção e intuição que também compõem o cotidiano dos estudantes e compreendem suas concepções de mundo, este artigo se encontra respaldado. A partir desta reflexão, considerando os apontamentos sobre o contexto do ensino do tema "solo" e os impasses que a formação de professores apresenta em relação às dicotomias do conhecimento de profissão e de mundo, analisaremos uma prática pedagógica para o ensino do conceito de solo que utilizou um elemento artístico, a poesia, como recurso problematizador da realidade, buscando entender como foi concebida por um grupo de universitários.

\section{DESENVOLVIMENTO}

A proposta pedagógica a ser analisada aconteceu durante um curso de verão realizado na Universidade Federal de Lavras que envolveu estudantes de graduação e pós-graduação, em que foi proposto aos participantes do evento que construíssem e aplicassem planos de aula à nível de ensino fundamental que tenha como recurso problematizador uma obra literária. Uma característica que essas aulas não poderiam possuir é a exposição e demonstração dos conteúdos, ou seja, não poderiam se enquadrar nas chamadas metodologias de ensino tradicionais que colocam os estudantes em modo passivo no processo de ensino e aprendizagem, comumente memorizando conceitos que são transmitidos do professor, detentor do conhecimento, para o aluno. Estas propostas devem, portanto, se aproximar das chamadas metodologias ativas de ensino.

Segundo Diesel, Baldez e Martins (2017), os princípios das metodologias ativas de ensino se encontram em alguns aspectos, como desenvolver a autonomia dos estudantes; se desenvolver no sentido em que estes sejam o centro do processo de ensino e aprendizagem; proporcionar uma reflexão sobre o mundo a partir da problematização da realidade; ter o professor como mediador e facilitador do processo de apropriação dos conceitos e, portanto, reflexão sobre a realidade; e que este profissional se inove na direção de propor um percurso metodológico diferente dos percursos tradicionais de ensino, de modo a possibilitar uma transformação no cenário educacional (DIESEL, BALDEZ \& MARTINS, 2017).

A aula foi ministrada por 2 professores. Inicialmente os professores apresentaram o tema para os outros participantes do curso de verão e perguntou a eles se gostavam de poesia. Alguns responderam que sim e, após isso, um dos professores recitou o poema "Quando matam um sem-terra" do autor Pedro Munhoz. Após à declamação do poema foi perguntado aos participantes se gostaram da obra e se havia algum ponto nela que eles tenham gostado mais ou alguma parte que tenha chamado a atenção deles. Uma participante disse que o poema era bem "pesado", pois contava sobre a morte de alguém. Partindo dessa fala os professores foram questionando outros elementos da fala da aluna, como por exemplo "quem morreu?", "como é 


\section{Revista Científica ANAP Brasil}

ISSN 1984-3240 - Volume 13, número 31, 2020

chamado o grupo várias outras pessoas estão na mesma condição da pessoa que morreu?", "mas por que o homem foi morto?". A partir daí foi discutido com outras falas dos alunos quem era o MST e seus objetivos, além da questão da terra que vem como eixo central do poema. Depois de conversar sobre estes elementos que o poema proporcionou discutir, foi questionado sobre o nome "terra" que o poema trouxe e quais outros nomes os participantes conheciam além deste. Disseram outras duas palavras "chão" e "solo". Com isso, os professores começaram a diferenciar a palavra "solo" das outras trazendo que esta última é uma palavra técnica, e que apresenta um conceito. Assim, foi trazida uma imagem de uma cultura orgânica impressa e foi perguntado sobre o que era visto nela que representava alguns componentes do se chamava de solo. Antes disso, os professores contaram para a turma o que era "cultura orgânica". Os participantes trouxeram os vegetais, os animais, a água e o ser humano contido na imagem. Os professores acrescentaram que a parte vermelha, ou seja, mineral, também fazia parte, assim como a matéria orgânica que compunha a camada chamada de húmus. Depois de discutirem, os professores disseram que era uma imagem retirada do site do MST, e que este grupo era o maior produtor orgânico do Brasil. Ao extraírem os elementos visíveis que compõem o solo a partir da imagem, os professores trouxeram outros dois, que são: ar e microrganismos. Então, foi questionado aos participantes "de onde vem o solo?". Os professores, juntamente com os alunos, construíram a ideia de que as rochas são quebradas em pedaços cada vez menores, ou seja, ela ia se decompondo em partículas pequenas chamadas areia, silte e argila. Desse modo, os professores trouxeram que existem vários tipos de solos que variam entre o tamanho de suas partículas, em um gradiente entre arenoso e argiloso. A cada momento que era trazidos os componentes do solo os professores iam recapitulando para que não fossem esquecidos. Quando a parte de discussão dos conceitos terminou, os professores pegaram uma imagem capturada do ambiente ao redor de onde aconteceu a aula que trazia a entrada de um formigueiro no solo e perguntou aos alunos se naquela imagem havia solo. Disseram que sim, e identificaram novamente os componentes. Com isso, os professores perguntaram se alguém sabia o que havia dentro do formigueiro e, antes que alguém respondesse, eles pediram para não contar agora, pois eles fariam isso de outra maneira. Assim, foi pedido para que cada participante contasse uma história de como seria se eles fossem um animal pequeno o bastante para adentrar o formigueiro e visse tudo que havia lá. Não se resumindo a isso somente, foi acrescentado que os alunos deveriam mobilizar os conceitos aprendidos durante a aula, como formação do solo e composição do solo, onde os professores recapitularam com a turma antes de começar a atividade avaliativa. Após terem produzido as histórias, cada aluno apresentou para toda a turma e a aula terminou.

\section{METODOLOGIA}

Neste tópico delinearemos o caminho que possibilitará analisarmos a proposta pedagógica relatada no tópico anterior. Para isso, olharemos para as falas dos envolvidos que participaram da aula e a avaliaram em pontos positivos e em pontos a serem melhorados. Este trabalho, portanto, se enquadra em uma pesquisa qualitativa, uma vez que o objeto de estudo será analisado pelo conteúdo de suas falas - levando em consideração a experiência dos pesquisadores em consonância ao referencial adotado (FLICK, 2008). 
Trazido o contexto que originou esta prática pedagógica e sua aplicação para um grupo de universitários, definiremos quem são estes. Os participantes foram nomeados com a letra " $A$ " seguida de um número, de modo a preservar a identidade de cada um. Primeiro, deve-se destacar que dois universitários (A4 e A8) não estavam cursando licenciatura durante o curso de verão em que aconteceu a ministração da aula, sendo um do curso de agronomia e outro do curso de engenharia florestal. Os outros seis universitários compreendem dois integrantes de mestrado ( $A 2$ e $A 5$, que cursaram licenciatura em ciências biológicas) e quatro graduandos ( $A 1$, A3, A7, A7) em ciências biológicas licenciatura.

Para analisar as falas optou-se pelo método de categorização de falas proposto por Minayo, Deslandes e Gomes (2016). Dessa maneira, as ideias mais frequentes neste grupo de universitários serão agrupadas em categorias. Além das ideias mais frequentes, queremos entender o que este grupo expressou sobre a poesia utilizada na prática pedagógica, assim, agruparemos as falas referentes em uma categoria.

\section{RESULTADOS E DISCUSSÃO}

Com a análise e categorização das falas, as mesmas foram agrupadas em três categorias descritas, como pode ser observado na tabela a seguir:

Tabela 1: Descrição das categorias

\begin{tabular}{|c|c|c|c|}
\hline Categorias & Descrição & Frequência & Ocorrência \\
\hline $\begin{array}{l}\text { Aula dinâmica } \\
\text { que } \\
\text { proporcionou a } \\
\text { participação dos } \\
\text { alunos }\end{array}$ & $\begin{array}{c}\text { Nesta categoria os graduandos apontaram que a } \\
\text { aula proporcionou a participação dos mesmos por } \\
\text { ser dinâmica e interativa }\end{array}$ & 4 & $\begin{array}{c}A 5, A 6, A 7, \\
A 8\end{array}$ \\
\hline $\begin{array}{l}\text { Os professores } \\
\text { se mostraram } \\
\text { preparadose } \\
\text { com um bom } \\
\text { domínio do } \\
\text { conteúdo }\end{array}$ & $\begin{array}{l}\text { Nesta categoria foram reunidas as falas dos } \\
\text { graduandos que se remetem ao domínio do } \\
\text { conteúdo científico por parte dos professores }\end{array}$ & 4 & $\begin{array}{c}A 2, A 5, A 6, \\
A 7\end{array}$ \\
\hline $\begin{array}{l}\text { A poesia como } \\
\text { recurso } \\
\text { problematizador }\end{array}$ & $\begin{array}{c}\text { Aqui os graduandos destacaram que a poesia foi } \\
\text { um recurso interessante para problematizar o } \\
\text { assunto }\end{array}$ & 3 & $A 1, A 3, A 5$ \\
\hline
\end{tabular}

Nesta tabela podemos observar que os universitários (quatro deles) apontaram para a dinamicidade da aula, o que proporcionou, segundo eles, maior participação dos mesmos - e para o domínio do conteúdo que os professores apresentaram durante a aula. Ao olharmos para as falas que se remetiam à poesia, os sujeitos destacaram que a utilização da poesia como 


\section{Revista Científica ANAP Brasil}

ISSN 1984-3240 - Volume 13, número 31, 2020

recurso problematizador foi interessante. Partindo disso, discutiremos cada categoria na ordem em que foram descritas.

$\mathrm{Na}$ primeira categoria "Aula dinâmica que proporcionou a participação dos alunos" consideramos as falas que se remetiam à palavra "dinâmica" ou que traga sentido semelhante, além das ideias que se desdobrem a partir disso, ou seja, o que os alunos trouxessem como consequência deste tipo de aula que, no caso, foi apontada a participação dos envolvidos. Houve falas mais detalhadas, em que alguns sujeitos descreveram com mais palavras sobre o aspecto da aula apontado, já outros foram bem sucintos, como podemos observar nas falas a seguir:

\footnotetext{
"A5: a aula foi bem dinâmica [...] Os alunos participaram bastante devido à dinâmica que foi imposta na aula."

"A6: a aula foi bem dinâmica, buscou a participação dos educandos."

"A7: aula interessante, instigante, ajuda a pensar melhor sobre a formação do solo. Casou interação entre os alunos."

"A8: aula dinâmica e objetiva."
}

Podemos observar que três sujeitos usaram somente a palavra "dinâmica" para se referir à aula como um todo, e um deles trouxe na mesma direção com outras palavras, e que dois sujeitos destacaram a participação como uma característica da proposta pedagógica ministrada.

Sobre essa questão, a dinamicidade de uma aula está diretamente relacionada ao papel dos personagens no processo de ensino e aprendizagem. Em uma aula conservadora, baseada na exposição e memorização de conteúdo, onde este é transmitido do professor para o aluno, temse claro os papéis, o professor é o detentor do conhecimento e deve transmitir através da reprodução de textos no quadro e pela fala oral. Entretanto, visando uma transformação do cenário da educação, têm-se estratégias em que os papéis são transformados. Nessas o aluno passa a ser mais ativo e participante e o professor passa a tomar uma posição mais de mediador, proporcionando ao aluno ser autor, também, da construção de seu aprendizado.

Tortella, Tassoni e Megid (2014) discutem nesse sentido trazendo que a relação entre os alunos durante o processo pedagógico é fundamental para a construção do conhecimento e da autonomia. Segundo estas autoras, a troca de informações, de dúvidas, de soluções e demais outros elementos que compreendem o processo de ensino e aprendizagem contribuem para que os estudantes se formem mais consistentemente. Dessa maneira, o que 4 universitários apontaram a respeito da prática pedagógica analisada em questão mostra que, mesmo os sujeitos não descrevendo com mais detalhes sobre essa dinamicidade, a participação que é um desdobramento, foi um aspecto interessante.

Em consonância às ideias anteriores, trazendo a discussão de Damiani (2008) sobre o trabalho colaborativo na escola, uma aula dinâmica que estimule a interação entre os alunos e eles com o professor pode ajudar os estudantes a desenvolverem a argumentação. Quando estes se colocam no coletivo têm a possibilidade de desenvolver a socialização, a superação do egocentrismo e demais outros aspectos que contribuem para a formação do sujeito enquanto ser humano por meio do processo de escolarização.

Por outro lado, quando vamos pensar uma prática pedagógica não podemos deixar de pensar sobre o conteúdo a ser ensinado. Por muitos anos o ensino tradicional ou conservador esteve e ainda está nas escolas, e o professor, como já dissemos, têm o papel de detentor do 
conhecimento a ser passado adiante. Em uma metodologia ativa em que há a participação dos estudantes no processo de construção do aprendizado, por exemplo, o professor, por mais que ele atue diferentemente de uma aula conservadora, também deve possuir o domínio do conteúdo (conhecimento. Portanto, além de outros conhecimentos, o professor deve dominar o conhecimento da área que vai lecionar, e isso está relacionado à segunda categoria elencada nas falas.

Agora em "Os professores se mostraram preparados e com um bom domínio do conteúdo" os universitários reconheceram outro aspecto da proposta pedagógica e que está ligado ao domínio do conteúdo e preparo do professor para desenvolver a aula com segurança, que o professor adquire durante sua formação específica e seu exercício profissional, o que envolve um bom planejamento. Antes de discutirmos de forma aprofundada, ilustraremos as falas dos participantes que se remetem à questão:

\footnotetext{
"A2: Boa apropriação do conteúdo para o desenvolvimento da aula."

"A5: [...] os professores dominaram bem os conteúdos."

"A6: [...] ministrando com clareza os conteúdos, trabalhando-os de forma segura."

"A7: Professores mostraram bem preparados."
}

O domínio do conteúdo está intimamente ligado ao preparo e planejamento do professor. $\mathrm{Na}$ fala do A6 ele relata que os professores se apresentaram seguros e claros quanto ao desenvolvimento do conteúdo com a turma. Em relação a isso, Longhini (2008) concluiu que o domínio do conteúdo influencia a forma como o professor lida com as questões que surgem em sala de aula, seja na própria explicação de um tema, seja na resposta a uma dúvida de um estudante ou até mesmo em saber mobilizar as falas que os alunos trazem durante a aula.

Mesmo sua pesquisa sendo em campo da pedagogia, revelou que o domínio do conhecimento específico é crucial para o exercício da profissão docente, uma vez que obstáculos conceituais impedem o aprendizado efetivo dos estudantes, em que não há clareza e segurança no discurso do professor, ainda que em alguns casos os alunos podem demonstrar um conhecimento mais complexo sobre o assunto que o próprio professor, dificultando ainda mais o desenvolvimento da aula pelo docente. Além disso, este autor chama a atenção para o fato de muitos professores utilizarem dos livros didáticos para estudarem sobre os conteúdos que vão ensinar, o que é problemático, pois muitos dos livros didáticos possuem erros conceituais (LONHGINI, 2008). Em relação à terceira categoria, identificamos que três universitários citaram a poesia utilizada como recurso problematizador da proposta pedagógica em questão. Antes de discutirmos ilustraremos as falas dos envolvidos:

\footnotetext{
"A1: o poema foi utilizado com muita pertinência na aula, pois as problematizações acerca da composição do solo partiram da realidade que o poema retrata e ainda incorporou com espontaneidade a participação dos alunos.

“A3: o poema foi muito bem utilizado para dar início à problematização.

"A5: Houve um bom diálogo com a poesia."
} 


\title{
Revista Científica ANAP Brasil
}

\author{
ISSN 1984-3240 - Volume 13, número 31, 2020
}

Como podemos observar os universitários apontaram que houve um bom diálogo da poesia com a problematização do tema da aula, que é o conceito de solo. Dois deles citaram a palavra "problematização" para se referir a como este recurso se comportou na aula em questão que, neste caso, era o objetivo proposto. A pedagogia da problematização não valoriza transmissão de ideias prontas ou comportamentos ideais, nem mesmo soluções para questões cotidianas, mas fazer com que o estudante olhe para a realidade e consiga pensar sobre ela a partir do exercício de fazer perguntas relevantes sobre os elementos que a compõe (BORDENAVE, 1999). Neste sentido, a poesia foi a janela para a realidade em que os universitários puderam confrontá-la e problematiza-la pela mediação dos professores.

Vale ressaltar que estes universitários fizeram ou fazem parte de um curso de licenciatura, o que pode ter influenciado o olhar destes sobre este aspecto da proposta pedagógica, considerando que dois sujeitos do grupo fazem parte de cursos bacharéis. Mesmo a frequência sendo menor que as demais categorias, vale o esforço em discutir o papel que a arte (poesia) pode ter no âmbito educacional.

Rangel e Rojas (2014) trazem a importância de haver uma aproximação entre arte (poesia) e ciência, em que estas autoras discutem o papel imaginativo que existe nestes dois olhares sobre o mundo. A arte traz a sensibilidade para as reflexões, estimulando a imaginação dos estudantes, o que se comportou como um meio interessante para se discutir aspectos da realidade, segundo os universitários.

Em diálogo com a ciência, portanto, o processo de humanização em sala de aula se torna mais completo, pois os estudantes poderão, em conjunto, trocar experiências, expressar sentimentos, emoções, valores e intuições que fazem parte de seus cotidianos e, assim, construir o conhecimento sistematizado, este que os próprios estudantes terão a oportunidade de entender que os variados conceitos aprendidos estão expressos em elementos culturais, além dos livros didáticos, experimentos científicos ou demais recursos apropriados pelo professor. Estas autoras reforçam que a arte e a ciências são produtos da expressão humana que apresentam características comuns, como a criação, investigação e o poder de propor explicações sobre o mundo, e devem ser trabalhadas em conjunto (RANGEL \& ROJAS, 2014), mesmo que essencialmente se apresentem como linguagens muito diferentes.

\section{CONSIDERAÇÕES FINAIS}

A partir deste trabalho concluímos que a proposta pedagógica analisada apresentou impressões positivas pelo grupo de universitários que participou de sua realização. Uma característica destacada por este grupo foi a dinamicidade da aula, em que alguns ainda registraram a participação dos envolvidos como outro aspecto da aula em questão. Segundo o referencial adotado, aulas dinâmicas e que estimulam e exercitam a participação e interação entre os personagens dentro da sala de aula é um fator fundamental para a construção dos estudantes enquanto seres humanos, em que eles têm a possibilidade de desenvolver sua socialização, argumentação e demais aspectos que compreendem um ser humano.

Sobre o domínio do conteúdo e preparo do professor, os universitários levantaram um ponto importante. Para se ensinar determinado tema o professor precisa possuir conhecimento a respeito do mesmo, ou o contrário pode levar à problemáticas no processo de ensino e 


\section{Revista Científica ANAP Brasil}

ISSN 1984-3240 - Volume 13, número 31, 2020

aprendizagem como pôde ser visto na discussão. Um profissional da educação que se apresente deficitário sobre o conteúdo a ser ensinado terá dificuldades em desenvolver o assunto em sala de aula, o que envolve encontrar obstáculos conceituais em lidar com as dúvidas e falas dos alunos ao decorrer do processo. Sendo assim, o domínio do conteúdo e estar preparado para ministrar uma aula são fatores decisivos e fundamentais em uma prática docente.

Quando olhamos para a poesia três dos envolvidos se remeteram a este recurso. Deixaram claro que a poesia foi um interessante recurso problematizador da aula, o que está em diálogo com o referencial adotado. Rangel e Rojas (2014) defendem a aproximação da arte e da ciência para uma formação humanizadora mais completa, em que as contribuições sensíveis, emocionais, imagéticas e intuitivas da poesia, em consonância com a ciência, podem agir no sentido de promover um aprendizado mais consistente. Isso porque, segundo as autoras, arte e ciência são produções criativas exclusivas do ser humano.

\section{AGRADECIMENTO}

CAPES E FAPEMIG.

\section{REFERÊNCIAS BIBLIOGRÁFICAS}

BORDENAVE, Juan E. Dias et al. Alguns fatores pedagógicos. Capacitação em desenvolvimento de recursos humanos CADRHU, p. 261-268, 1999.

BRASIL. Base Nacional Comum Curricular. Brasília: MEC, 2017. Disponível em: http://basenacionalcomum.mec.gov.br/images/BNC_El_EF_110518_versaofinal_site.pdf. Acesso em: 05 de maio de 2018.

DAMIANI, Magda Floriana. Entendendo o trabalho colaborativo em educação e revelando seus benefícios. Educ. rev., Curitiba, n. 31, p. 213-230, 2008.

DIESEL, Aline; BALDEZ, Alda Leila Santos; MARTINS, Silvana Neumann. Os princípios das metodologias ativas de ensino: uma abordagem teórica. Revista Thema, v. 14, n. 1, p. 268-288, 2017.

FLICK, Uwe. Introdução à pesquisa qualitativa-3. Artmed editora, 2008.

GATTI, Bernardete A. Formação de professores no Brasil: características e problemas. Educação \& Sociedade, v. 31, n. 113, p. 1355-1379, 2010.

LIBANEO, José Carlos. Formação de professores e didática para desenvolvimento humano. Educação \& Realidade, Porto Alegre, v. 40, n. 2, p. 629-650, 2015.

LIMA, Marcelo Ricardo de. O solo no ensino de ciências no nível fundamental. Ciência \& Educação (Bauru), v. 11, n. 3, p. 383-395, 2005.

LONGHINI, Marcos Daniel. O conhecimento do conteúdo científico e a formação do professor das séries iniciais do ensino fundamental. Investigações em Ensino de Ciências, v. 13, n. 2, p. 241-253, 2016.

MINAYO, Maria Cecília de Souza; DESLANDES, Suelen Ferreira; GOMES, Romeu. Pesquisa Social: Teoria, método e criatividade. Petrópolis: Editora Vozes, 2016, 95 p.

OLIVEIRA, Déborah de. O conceito de solo sob o olhar de crianças do Ensino Fundamental em escolas de São PauloSP. Ciência e Natura, v. 36, p. 210-214, 2014. 


\section{Revista Científica ANAP Brasil}

ISSN 1984-3240 - Volume 13, número 31, 2020

RANGEL, Mary; ROJAS, Angelina Accetta. Ensaio sobre arte e ciência na formação de professores. Revista Entreideias: educação, cultura e sociedade, v. 3, n. 2, 2014.

SANTOS, Wildson Luiz Pereira dos; MORTIMER, Eduardo Fleury. Abordagem de aspectos sociocientíficos em aulas de ciências: possibilidades e limitações. Investigações em ensino de Ciências, v. 14, n. 2, p. 191-218, 2016.

TORTELLA, Jussara Cristina Barboza; TASSONI, Elvira Cristina Martins; MEGID, Maria Auxiliadora Bueno Andrade. As Interaçoes em sala de aula. As prácticas pedagógicas e as possibilidades de aprendizagem. Diálogos Latinoamericanos, n. 23, p. 115-134, 2014. 